\title{
WORLDWIDE SURVEY OF AWARENESS AND NEEDS CONCERNING REANALYSES AND RESPONDENTS VIEWS ON CLIMATE SERVICES
}

by H. Gregow, K. Jylhä, H. M. Mäkelä, J. Aalto, T. Manninen, P. Karlsson, A. K. Kaiser-Weiss, F. Kaspar, P. Poli, D. G. H. Tan, A. Obregon, and Z. Su

Results of a worldwide online survey for reanalysis users provide valuable insight for removing obstacles that hinder the use of reanalyses in climate services.

T he World Meteorological Organization (WMO) defines climate services as the provision of climate information prepared and defined to meet users' needs (WMO 2011). Such climate services could thus include a variety of sector-specific climate research

AfFiliations: Gregow, Jylhä, Mäkelä, Manninen, and KARLSSON-Finnish Meteorological Institute, Helsinki, Finland; AALTO-Finnish Meteorological Institute, and Department of Geosciences and Geography, University of Helsinki, Helsinki, Finland; KAISER-WEISS AND KASPAR-Deutscher Wetterdienst, Offenbach, Germany; POLI AND TAN-European Centre for Medium-Range Weather Forecasts, Reading, United Kingdom; OBREGON-Group on Earth Observations Secretariat, Geneva, Switzerland; Su-University of Twente, Enschede, Netherlands CORRESPONDING AUTHOR: Hilppa Gregow, Finnish Meteorological Institute, P.O. Box 503, FI-00I0I Helsinki, Finland E-mail: hilppa.gregow@fmi.fi

The abstract for this article can be found in this issue, following the table of contents.

DOI:I0.II75/BAMS-D-I4-0027I.I

In final form 24 November 2015

(C)2016 American Meteorological Society (e.g., Hartmann et al. 2013), including investigations into past, current, and future climate as well as associated observed and projected trends. The process of linking the climate data production with user demands is a complex one (McNie 2013) and requires codesign (Bradwell and Marr 2008). WMO also emphasizes that the development of climate services should extend beyond traditional meteorological information to encompass nonmeteorological data in the areas of agriculture, health, infrastructure, and various other socioeconomic considerations.

There are increasing efforts to improve the delivery of climate services at national, regional, and global levels. These efforts include Global Framework for Climate Services (GFCS; Hewitt et al. 2012) and Copernicus Climate Change Service (C3S). The aim of the GFCS, led by WMO, is to strengthen the provision and use of climate predictions, products, and information worldwide, and the vision of the $\mathrm{C} 3 \mathrm{~S}$ is to provide an authoritative source of qualityassured climate information for Europe and globally. Furthermore, a European research and innovation Roadmap for Climate Services has been recently 
elaborated by an expert group established by the European Commission (Street et al. 2015).

Given the scales and ambition of envisaged climate services, there are many challenges to be addressed. Among other contributory factors, two salient considerations may be highlighted: 1) The climate services' end user community is not fully known in advance; besides well-known, identifiable users (e.g., governments at various levels), the need for climate-sensitive information pervades many areas of society, and so the user base is poised to grow with the increased accessibility of information. 2) Even if the needs of an end user group were very well known, it may not be straightforward to fully meet them. For example, when delivering observational data, the inevitable limitations of the observing systems need to be acknowledged. Neither in situ measurements nor remotely sensed ones cover all the temporal and spatial scales that are requested by users. Both considerations should be kept in mind when addressing the challenging question of whether a produced and delivered piece of climate information is fit for purpose.

Typically, climate observations are generated by a diverse combination of instrumentation and computational processing, and the observation density changes over time and location. For these reasons, careful harmonization of observational datasets is essential. A range of different techniques are available for interpolating spatially irregular marine and meteorological observations to regular grids. Examples include the European daily high-resolution gridded dataset (E-OBS) for Europe (Hofstra et al. 2008), the Global Historical Climatology Network for land station observations (Menne et al. 2012), the International Comprehensive Ocean-Atmosphere Dataset for surface marine observations (Woodruff et al. 2011), and the Global Precipitation Climatology Centre (Becker et al. 2013) at the global scale, in addition to many products at national levels, for example, over Finland (Aalto et al. 2013).

Besides utilizing gridded climate observational datasets, climate service provision may benefit from assimilation-based reanalysis activities. These extend beyond traditional reanalysis dataset production to related activities such as observational dataset evaluation. Currently there are more than 15 (40) atmospheric (oceanic) global reanalyses produced by different institutions. The reanalysis systems employed aim for a consistent analysis of archived Earth observations (preferably those that have undergone reprocessing; Bosilovich et al. 2013), using a modern analysis and forecasting system (Dee et al. 2014). With such systems it is possible to derive estimates for the atmosphere-ocean-Earth system state in a scientifically traceable manner and approaching the quality needed for the most demanding climate applications. The assimilationbased algorithms spread information from observed parameters and locations to times and locations where the in situ or satellite data coverage is poor or nonexistent.

For supporting climate services, there is a growing need for characterization and communication of dataset uncertainties. This applies both to "purely observational" datasets (e.g., in case of the E-OBS dataset; Hofstra et al. 2010) and to reanalysis datasets. The comprehensive range of geophysical parameters and spatiotemporal scales available in a reanalysis dataset, together with the complexities of modern analysis/forecast techniques, means that reanalysis uncertainty characterization is a significant challenge. It requires a close and sustained cooperation between reanalysis producers and the wider climate service community, including the user application and science communities. Mechanisms to facilitate the sharing of knowledge will be vital, and we thus acknowledge the richness of the exchanges and comments posted on the community forum website reanalyses.org.

With such considerations in mind, it was decided to conduct a worldwide user survey of awareness and needs concerning reanalyses and climate services. The main aim was to gather responses that would inform future development of reanalyses in support of climate services. A goal of the survey was also to foster discussion with users with a view to engaging in closer cooperation. A previous reanalysis user survey, namely, about 40-yr European Centre for Medium-Range Weather Forecasts (ECMWF) ReAnalysis (ERA-40; Uppala et al. 2005), was conducted in 2004/05 (Hollingsworth and Pfrang 2005). Most of the 127 respondents gave positive feedback about the quality and accessibility of the ERA- 40 data. That survey revealed that users desired increased resolution, longer time spans, and more regular extensions of the time series to the present. Despite the relatively small number of respondents, the survey provided valuable input for shaping the definition of ECMWF interim reanalysis (ERA-Interim; Dee et al. 2011) and ECMWF twentieth-century pilot reanalysis (ERA20C; Poli et al. 2013), with the former continuing into the present and the latter covering the entire twentieth century.

The new survey reported in the current article was conducted in the period from November 2013 to February 2014. The survey elicited responses from 
2,578 users of climate information drawn from 10 sectors (private, education, etc.) and 28 fields of work (weather, climate, ecosystems, etc.). Recognizing the interest within the GFCS and C3S in agriculture and food security (Tall et al. 2014), disaster risk reduction, health and water resources, and, since 16 January 2015, also energy [WMO summary statement on the Second Session of the Intergovernmental Board on Climate Services (IBCS-2) conference], we present analyses of all responses as well as responses from sectoral groups who focus their work on water management, agriculture, forestry, and energy. The results summarized in this paper are offered as a contribution to wider consultation processes for shaping global, intergovernmental, and national climate service initiatives.

MATERIAL AND METHODS. Survey scope, advertising, and response rate. Our survey aimed at ascertaining user awareness and needs concerning reanalyses to guide the development of reanalyses in support of climate services. Devised and conducted within the frame of a European-funded coordination project [Coordinating Earth Observation Data Validation for Re-Analysis for Climate Services (CORE-CLIMAX)], we nonetheless sought and accepted responses worldwide. The respondents were queried about four main themes: 1) demographics and scientific background, 2) their use of data and applications, 3) their awareness and needs in regard to reanalyses, and 4) their perceptions of climate services. For each theme, two or three main questions were presented with several subsections (more information can be found online at http://dx.doi .org/I0.I I75/BAMS-D-14-0027I.2). This paper briefly addresses themes 1 and 2 with an emphasis on themes 3 and 4.

The survey was put online for around 105 days. It was launched on November 2013 by the Finnish Meteorological Institute (FMI) and by WMO; the latter sent an invitation letter (see the supplemental information, section labeled "Please take part in the reanalysis user and application survey") to its focal points who then distributed it further. During the next two weeks, the survey was posted on the project web pages, on FMI internal web pages, and, with help from the National Oceanic and Atmospheric Administration (NOAA), on reanalyses.org. The closing of the survey was originally scheduled for the end of January 2014, but it was later postponed by a month (see the supplemental information).

The number of respondents first grew only gradually (Fig. 1). During the first two months the total number of respondents was 183 (and 64 left their contact information, hereafter CON). On 21-22 January a very successful effort was made to increase the response rate, as NOAA advertised the survey to the reanalysis community by sending messages to reanalysis_20cr-notify, all of NOAA Earth System Research Laboratory (ESRL), all of University of Colorado (CU)/Cooperative Institute for Research in Environmental Sciences (CIRES), and acre-discussion @met-acre.org, and ECMWF sent an e-mail to its registered users. Within the next five days we received an additional 1,332 responses (463 CON). During 26 January-23 February, the number of respondents increased by 203 ( 85 CON). A reminder by ECMWF on 24 February resulted in a new sharp peak, with 860 responses (292 CON) during the last five days before the survey was closed. That means that during the two 5-day periods, one in January and the other in February, following the e-mails from NOAA and ECMWF, altogether 2,192 respondents (755 CON) took part in the survey. Thus, we suspect that most of these respondents were directly influenced by the advertisements, whereas many of the remaining respondents (386 in total, 149 CON, or about 15\%) may have found the survey link more independently.

Collecting background information about the survey respondents. The first two of the four main themes that the respondents were queried about concerned demographics and scientific background (Q1-Q3, Q12) and the use of data and applications (Q4-Q6; see the supplemental information, section labeled "Reanalysis user and application survey"). Because the survey primarily focused on finding the specific needs of the respondents for the scientific development of reanalyses and climate service portfolio, traditional demographical information such as age, gender,

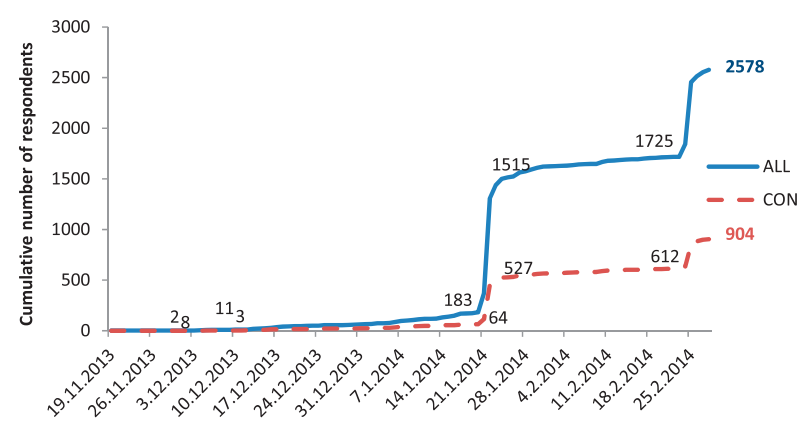

FIG. I. Response rate during the survey. Those leaving CON are shown with a dashed curve and ALL responses are shown with a solid curve. Correlation in time between the daily number of the responses from CON and ALL-CON is $r=0.993$. 


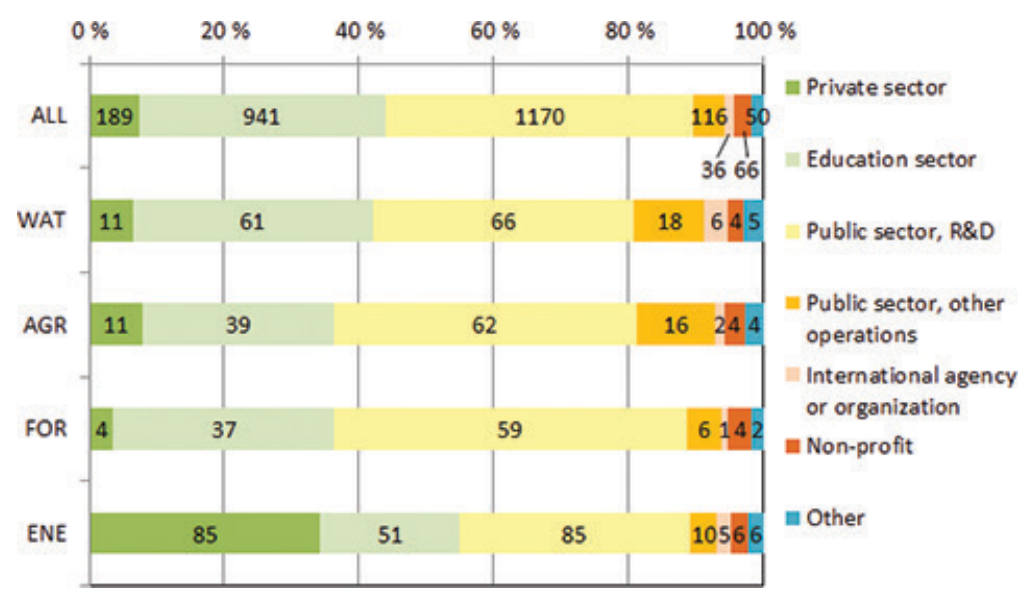

FIG. 2. Respondents' sector of work for ALL and the four subgroups. The numbers of respondents in each sector are also shown. climate services (Q10 and Q11; see the supplemental information, section labeled "Reanalysis user and application survey"). For question Q8 ("Regarding the characteristics of reanalysis data, would you say that...?"), a total of 23 statements were proposed, asking users to express their level of agreement/ disagreement on a five-point scale. For question Q10 ("Do you think that climate service should include the following tasks or activities?"), a total of 15 different future climate service tasks and activities were proposed. The total number of respondents was 2,486 for Q8 and 2,192 education, or income level were not asked. Instead, the survey queried the sector of work (or the employment type), discipline or subject of work, and the region of the world the respondent mainly focuses his work. Voluntary responses about contact information, including country of residence, were also welcomed (see CON in Fig. 1).

To describe their field or subject of work, respondents were offered the choice of 28 alternatives, and they were invited to select all the fields that applied.

In addition to the answers of all the respondents (ALL; 2,578 respondents), attitudes of four subgroups will be examined in this paper. The selected subgroups consisted of respondents declaring their main field or subject of work to be freshwater resources and management (WAT; 172), agriculture and food production (AGR; 139), forests (FOR; 113), or energy (ENE; 249).

The respondents' sectors of work (employment types) were analyzed for ALL and for the four subgroups. In addition, to ascertain if the advertisements of the survey by e-mails from NOAA and ECMWF had an influence on the demographical distribution of the respondents, we compared the sectors of work for ALL before 21 January 2014 and after that date.

To obtain further background information about the respondents, they were asked to state whether they use reanalysis data, and if so, they were invited to select all the reanalysis datasets that applied. Essential climate variables (ECV) were considered. Respondents were also asked about applications and methods used.

Analyses of the respondents' opinions and needs. The main aim of the survey was to identify awareness and needs of the respondents in regard to reanalyses (Q7-Q9, Q11) and their perceptions of for Q10. We used a five-level Likert scale, meaning that for each proposed statement, the respondents could select between five alternatives [from 1 (fully disagree) to 5 (fully agree)] or skip. Note that in this paper we use a reversed scale compared to the original one in the supplemental information (see the section labeled "Reanalysis user and application survey"). For each proposition, we calculated the mean and standard deviation across ALL and separately for the four subgroups (WAT, AGR, FOR, and ENE): the higher the mean, the higher level of agreement. For each statement, the statistical significance of the difference between the resulting mean and the median Likert item 3 was assessed using a two-sided one-sample Student's $t$ test.

To test for correlations between the answers of the subgroups, principal component (PC) analysis (PCA) was performed using the RDA function from the Vegan package (Oksanen et al. 2008) in $R$ (R Development Core Team 2013). This technique reduces the dimensionality in a dataset, searching for an arrangement that explains the most variation in the data. The best linear fit for each subgroup to the PCA ordination scores was determined, testing the significance of the fit using a permutation approach (implemented by the envfit function). For the analysis, the subgroups were coded as dummy variables ( 1 indicates "belongs to group"; 0 indicates "does not belong to group").

Free-form comments concerning reanalysis datasets (Q9) and future climate services (Q11) were analyzed only for the four selected subgroups. The share of respondents leaving free comments for Q9 was roughly one-third (from 34 respondents in FOR to 97 respondents in ENE) and less than one-fifth (from 21 respondents in FOR to 37 respondents in ENE) for Q11. 
After filtering out vague responses and answers of the type "no comment," the number of remaining responses decreased further. Two reviewers investigated the responses by reading and clustered those with clear suggestions and opinions. Because similar topics arose both in Q9 and Q11, the responses for these two survey points were merged. Because of the very subjective nature of their analysis, the free comments can only be handled as a presentation of a variety of opinions about the users' needs concerning reanalyses and climate services.

RESULTS. Demographics, scientific discipline, and regional focus of work. Based on CON provided by 907 (35\%) out of 2,578 respondents, people from at least 97 countries took part in the survey. The highest number (153) of CON came from China, second (81) from India, and third (71) from the United States. At least 30 contacts were also obtained from Germany, France, Italy, Spain, and Indonesia (Table S1).

Education and public research and development $(\mathrm{R} \& \mathrm{D})$ were among the most important fields of work for the respondents in China, India, Japan, and the United States. The private sector was represented especially by the United States, France, Germany, India, and Italy (not shown).

Considering ALL, WAT, AGR, and FOR, the majority ( $80 \%$ ) of respondents were from the education or public R\&D sectors. ENE was an exception in that the private sector was as numerous as the public R\&D sector (85 respondents or 34\%; Fig. 2). Respondents from public sector operations other than $\mathrm{R} \& \mathrm{D}$, from international agencies or organizations, and from the nonprofit sector appeared in the minority in the four subgroups.

We compared the respondents' sectorial distributions before and after 21 January 2014, the date of the first advertisements that were followed by the sharp increase in the number of responses (Fig. 1). No statistically significant difference was found (chi-squared test). This suggests that e-mailing by NOAA and/or ECMWF did not bias the demographical orientation of respondents, at least not for the distribution of sectors of work.
The two most prevalent fields or subjects of work for ALL were climate and weather, the former occurring among $73 \%$ of ALL and the latter among $47 \%$ of ALL (Table 1). Only $18 \%$ of ALL declared that their work involved neither. The subgroups appeared in the seventh position for ENE (10\% of ALL), ninth position for WAT (7\%), twelfth for AGR (5\%), and thirteenth for FOR (4\%). Because the survey invited respondents to choose all the fields that applied, these groups were partially overlapping. AGR and FOR had the largest proportion of common respondents.

The respondents reported geographical interest for the whole globe, Europe, and Asia, which were included in the six most popular regions for ALL and the four subgroups. The most common regional focus of work for the four subgroups was Europe, especially for ENE (50\%) but also for WAT, AGR, and FOR $(33 \%)$. For ALL, the whole globe was the most typical

\begin{tabular}{|c|c|c|c|c|c|}
\hline Weather\&Climate & 79 & $\Rightarrow 83$ & $\Rightarrow 61$ & $\Rightarrow 111$ & $\Rightarrow 959$ \\
\hline Only climate & 46 & $\sqrt{3} 31$ & $\sqrt{32}$ & \& 40 & $\Rightarrow 913$ \\
\hline Only weather & 9 & \2 & $\sqrt{2} 4$ & \& 29 & $\sqrt{240}$ \\
\hline Other & 38 & ת 23 & $\sqrt{16}$ & \& 69 & 8466 \\
\hline Total number of responses & 172 & 숨 139 & 全 113 & 술 249 & 个2578 \\
\hline Percentage of responses & $7 \%$ & $5 \%$ & $4 \%$ & $10 \%$ & $100 \%$ \\
\hline Climate & 125 & 全 114 & 仓 93 & $\Rightarrow 151$ & 宣1872 \\
\hline Weather & 88 & $\Rightarrow 85$ & $\Rightarrow 65$ & $\Rightarrow 140$ & $\Rightarrow 1199$ \\
\hline Oceans, seas & 44 & ป 30 & $\sqrt{2} 24$ & I. 64 & $\sqrt{ } 646$ \\
\hline Other aspects of atmosphere & 28 & \& 30 & \& 24 & 240 & \& 357 \\
\hline Air quality & 23 & \& 22 & ป 19 & 240 & 287 \\
\hline Snow, ice & & ป 22 & 23 & 28 & $\sqrt{283}$ \\
\hline Energy & 28 & ป 27 & $\sqrt{21}$ & 论 249 & $\sqrt{249}$ \\
\hline Geophysics/chemistry & 19 & ? 19 & 21 & ? 21 & $\sqrt{175}$ \\
\hline Water management & 172 & そ 35 & $\sqrt{26}$ & $\sqrt{28}$ & \& 172 \\
\hline Ecostystems, biodiversity & 32 & 840 & $\Rightarrow 53$ & 219 & 150 \\
\hline Geography & 29 & \ 28 & $\sqrt{25}$ & \& 21 & $\sqrt{147}$ \\
\hline Agriculture, food production & 35 & 论 139 & $\Rightarrow 42$ & \& 27 & $\sqrt{139}$ \\
\hline Forests & 26 & $\sqrt{2} 42$ & 삼 113 & \& 21 & \& 113 \\
\hline Safety & 22 & \& 13 & $\sqrt{11}$ & 27 & \& 102 \\
\hline Flooding of coastal areas & 29 & \20 & \& 15 & \& 26 & $\checkmark 101$ \\
\hline Transport & 14 & ป 18 & \& 12 & \& 30 & 877 \\
\hline Geoinformatics & 14 & マ 15 & $\sqrt{10}$ & $\checkmark 13$ & $\sqrt{73}$ \\
\hline Well being & 11 & ป 16 & $\sqrt{14}$ & \& 19 & $\sqrt{61}$ \\
\hline Industry & 9 & ป 8 & 27 & ₹ 39 & 246 \\
\hline Geology & 11 & \ 10 & 39 & 27 & \& 41 \\
\hline Economics & 8 & \& 15 & ป 9 & \& 20 & $\sqrt{35}$ \\
\hline Insurance & 9 & \& 14 & $\sqrt{10}$ & \& 12 & $\sqrt{35}$ \\
\hline Construction and engineering & 7 & マ 8 & $\checkmark 5$ & \& 13 & $\sqrt{34}$ \\
\hline Communication & 7 & マ 4 & 26 & \& 6 & $\sqrt{29}$ \\
\hline Urban or other design & 6 & 8 & \& 6 & \& 12 & 820 \\
\hline Tourism & 8 & 88 & 89 & 212 & 220 \\
\hline Other social aspects & 6 & ป 4 & 85 & 86 & \& 10 \\
\hline Indigenous peoples issues & 4 & ป 6 & 85 & \& 5 & 88 \\
\hline
\end{tabular}

TABLE I. Work focus distribution of ALL and the four subgroups. The respondents were asked to choose all that apply: arrow up indicates the highest percentage $(67 \%-100 \%)$ of responses, arrow right indicates the medium share (34\%-66\%), and arrow down indicates the lowest share ( $1 \%-33 \%)$ of responses within each main field of work. 
regional focus of work ( $32 \%$ of the respondents). Also Africa was included in the six most popular regions for ALL and the four subgroups. In addition to these, ALL concentrated also on the oceans [Pacific Ocean (9\%) being fourth and "Mostly oceans" (8\%) being sixth position]. AGR focused on continents with developing countries [International Monetary Fund (IMF) definition], with Africa (27\%) being in second and South America (20\%) being in fourth position; FOR focused on continents ["Mostly continents" (23\%) being in fourth position]; and WAT (19\%) and ENE (12\%) focused on specific countries ("Specific countries" being in fourth position for both of them).

Reanalysis products used. Among ALL respondents, the largest counts for the use of different atmospheric reanalyses were for ERA-Interim (2,049/2,578; 79\%); ERA-40 (1,325; 51\%); National Centers for Environmental Prediction (NCEP)-National Center for Atmospheric Research (NCAR) reanalyses (R1; 1,010; 39\%); NCEP-DOE Atmospheric Model Intercomparison Project phase 2 (AMIP-II) reanalysis (R2; 592; 23\%); and NCEP [Climate Forecast System Reanalysis (CFSR; 572; 22\%; Table 2]. ERA-Interim alone was used by 391 respondents (15\% of ALL), whereas 241 respondents (9\%) did not use any atmospheric reanalysis by ECMWF and 90 (3.5\%) declared not using any reanalysis products at all. For a more complete list of atmospheric and oceanic reanalysis datasets used by ALL respondents, see Gregow et al. (2015).

We also investigated usage counts for each of the four subgroups (Table 2). For subgroups WAT and AGR, ERA-Interim and ERA-40 were the most used reanalyses and NCEP reanalyses were the second most used. But for FOR and ENE, only ERA-Interim was clearly most used, whereas the NCEP reanalyses and ERA-40 were the second most used. Additionally, the proportion of ENE using National Aeronautics and Space Administration (NASA) Modern-Era
Retrospective Analysis for Research and Applications (MERRA) as well as the proportion of ENE and FOR using NCEP-DOE AMIP-II (R2) was rather high.

User awareness and needs in regard to use of reanalyses. Regarding the statements about the characteristics of reanalysis data, the mean scores given by ALL ranged from 3.1 to 3.9 , and the standard deviations ranged from 0.9 to 1.3 (Table 3). The average across all the statements was 3.5 , and the standard deviation of the mean scores was 0.3 . The statements were phrased such that higher scores meant greater satisfaction with the characteristic, and lower scores meant more dissatisfaction.

When considering ALL, the propositions invariably obtained a score that was statistically significantly higher than the midpoint of the Likert scale (Table 3). This implies that the respondents were satisfied rather than unhappy with the characteristics of reanalysis data. On average, the respondents most strongly agreed with the proposition that "The data is easy to access." On the other hand, the propositions having the lowest statistical significance (two-sided $p$ value between 0.002 and 0.01 ) and thereby exhibiting the least satisfaction were "The uncertainties are well characterized," "Plentiful training material is available on the web," and "I know how much the temporal true (feature) resolution differs from the nominal resolution in time." It is noteworthy that these proportions, together with a few other statements, had a high portion $(50 \%-60 \%)$ of respondents being "in between" or not answering at all (Fig. 3). This suggests that the issues in question may have been unimportant or unclear for many respondents. The results can be taken as an indication of the areas where there is need for future reanalysis development and increasing the awareness of the user community.

When considering the four subgroups separately, the need for further work related to the characteristics of

\begin{tabular}{|c|c|c|c|c|c|c|c|c|c|c|c|c|c|c|c|}
\hline $\begin{array}{l}\text { 놓 } \\
\frac{3}{5} \\
\text { 훙 } \\
\text { 흔 }\end{array}$ & 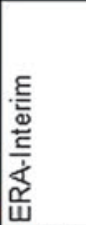 & $\begin{array}{l}\frac{P}{\dot{⿰}} \\
\text { 妥 }\end{array}$ & $\begin{array}{l}\frac{12}{\dot{d}} \\
\text { 点 }\end{array}$ & 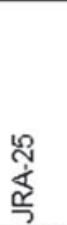 & 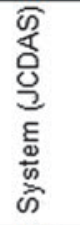 & 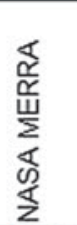 & 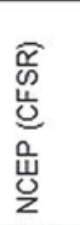 & 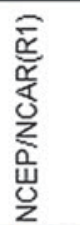 & 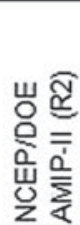 & 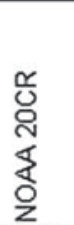 & 畄 & $\frac{\frac{\alpha}{\frac{\alpha}{5}}}{\frac{\alpha}{z}}$ & $\begin{array}{l}\sum \\
\text { ¿ } \\
\text { 旁 } \\
\text { W }\end{array}$ & 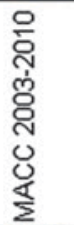 & 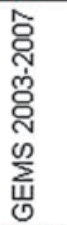 \\
\hline WAT & 숩116 & 令89 & ת 24 & 823 & ภ10 & $\sqrt{8} 40$ & $\Rightarrow 53$ & $\Rightarrow 66$ & ת 34 & $\sqrt{3} 30$ & 87 & $\sqrt{8} 31$ & 58 & $\sqrt{8} 10$ & \&11 \\
\hline AGR & 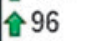 & 合81 & 凤 27 & 凤 23 & ภ 11 & ת 34 & $\Rightarrow 47$ & $\Rightarrow 58$ & ת35 & 凤 24 & \& 11 & $\sqrt{2} 20$ & \& 10 & \& 12 & ת 12 \\
\hline FOR & 삽 79 & $\Rightarrow 50$ & ת23 & ת 15 & ภ 7 & マ 21 & $\Rightarrow 37$ & $\Rightarrow 45$ & $\Rightarrow 31$ & 凤 19 & 85 & ת 15 & \& 10 & \& 10 & ภ 9 \\
\hline ENE & 令 196 & $\Rightarrow 110$ & ת. 31 & n. 30 & $\sqrt{3} 8$ & $\Rightarrow 87$ & $\Rightarrow 76$ & $\Rightarrow 87$ & ת 55 & 凤 32 & ת 10 & ป 30 & ת 10 & ู 17 & ת 13 \\
\hline ALL & , & $\Leftrightarrow$ & t & 4 & 14 & 4 & 14 & $\Leftrightarrow$ & 14 & 14 & te & 4 & 4 & 4 & 4 \\
\hline
\end{tabular}

TABLE 2. Atmospheric reanalysis datasets used by the respondents. Arrow codes are analyzed separately for ALL and each subgroup. The arrow codes are explained in Table $I$. 
reanalysis data and user awareness became even more obvious. Now several statements failed to achieve a statistically significantly score higher than 3 (Table 3). For example, the ENE respondents would appreciate, more clearly than ALL, improvements in spatiotemporal scales and more information about observation input to reanalysis. AGR and FOR shared the view with ENE that the data policy is somewhat restrictive and could be made easier and that the reanalysis data tend to become available too late. The WAT respondents especially wish for higher horizontal nominal (gridcell size) resolution and smaller biases compared with observations and tend to be worried about whether time-varying biases make the data too unstable for their needs.

In this context, it should be noted that survey respondents most commonly used reanalysis data for applications such as studies of atmospheric dynamics and physics and atmospheric and climate modeling (Table S2). The subgroups of WAT, AGR, FOR, and ENE also indicated time series analysis among the most common applications. ENE additionally uses reanalyses for resource assessment of renewable energies, WAT and AGR for studying climate change impacts, and WAT also for climate change detection.

\begin{tabular}{|c|c|c|c|c|c|c|c|}
\hline Statement about reanalysis data & mean & std dev & ALL $p$ & WAT $p$ & AGR $p$ & FOR $p$ & ENE $p$ \\
\hline The data are easy to access. & 3.9 & 1.2 & $* * *$ & $* * *$ & $* * *$ & $* * *$ & $* * *$ \\
\hline The data policy is NOT too strict. & 3.3 & 1.3 & $* * *$ & $* * *$ & - & - & - \\
\hline The file sizes are NOT too large to work with. & 3.4 & 1.2 & *** & $* *$ & $*$ & - & *** \\
\hline The data can be imported easily by my software application. & 3.7 & 1.2 & $* * *$ & *** & **** & $* * *$ & **** \\
\hline $\begin{array}{l}\text { The horizontal nominal (grid cell size) resolution is } \\
\text { adequate. }\end{array}$ & 3.4 & 1.2 & $* * *$ & - & $* *$ & $* *$ & $*$ \\
\hline The vertical nominal (grid cell size) resolution is adequate. & 3.6 & I.I & $* * *$ & *** & **** & $* * *$ & **** \\
\hline The temporal nominal resolution is adequate. & 3.6 & 1.2 & $* * *$ & $* * *$ & $* * *$ & $* * *$ & $*$ \\
\hline $\begin{array}{l}\text { For the climate variables I need, I know how much their } \\
\text { spatial true (feature) resolution differs from the nominal } \\
\text { resolution. }\end{array}$ & 3.1 & 1.2 & $* * *$ & $*$ & $* * *$ & $* * *$ & - \\
\hline $\begin{array}{l}\text { I know how much the temporal true (feature) resolution } \\
\text { differs from the nominal resolution in time. }\end{array}$ & 3.1 & 1.2 & $* *$ & - & $*$ & $* *$ & - \\
\hline $\begin{array}{l}\text { The spatiotemporal scales that I need are well } \\
\text { represented. }\end{array}$ & 3.4 & I.I & $* * *$ & $*$ & *** & $* * *$ & - \\
\hline The time period covers my interests. & 3.8 & 1.2 & $* * *$ & *** & $* * *$ & **** & **** \\
\hline The data are consistent between the variables. & 3.8 & 1.0 & $* * *$ & **** & 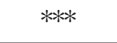 & $* * *$ & **** \\
\hline The general quality is good enough for my needs. & 3.8 & 1.0 & $* * *$ & $* * *$ & **** & $* * *$ & **** \\
\hline The biases compared with observations are small enough. & 3.3 & 0.9 & $* * *$ & - & **** & $* * *$ & ** \\
\hline $\begin{array}{l}\text { Time-varying biases DO NOT make the data too } \\
\text { instable for my needs. }\end{array}$ & 3.2 & 1.0 & $* * *$ & - & - & - & $* *$ \\
\hline The temporal continuity is adequate. & 3.7 & 1.0 & $* * *$ & $* * *$ & **** & $* * *$ & **** \\
\hline The uncertainties are well characterized. & 3.1 & 1.0 & $* *$ & - & - & - & - \\
\hline The observation input to reanalysis is clearly explained. & 3.1 & I.I & $* * *$ & - & $*$ & $* *$ & - \\
\hline I know enough to work with the data. & 3.6 & 1.0 & *** & $* * *$ & $* * * *$ & $* * *$ & **** \\
\hline $\begin{array}{l}\text { The data DO NOT tend to become available too late } \\
\text { for my needs. }\end{array}$ & 3.4 & 1.2 & $* * *$ & $* *$ & - & - & - \\
\hline Plentiful training material is available on the web. & 3.1 & 1.0 & $* *$ & - & $*$ & $*$ & - \\
\hline The literature provides good information. & 3.4 & 1.0 & $* * *$ & $* * *$ & **** & $* * *$ & **** \\
\hline Websites provide good information. & 3.5 & I.I & $* * *$ & $* * *$ & $* * *$ & $* * *$ & $* * *$ \\
\hline
\end{tabular}


THE DATA ARE CONSISTENT BETWEEN THE VARIABLES THE GENERAL QUALITY IS GOOD ENOUGH FOR MY NEEDS THE TEMPORAL CONTINUITY IS ADEQUATE THE DATA CAN BE IMPORTED EASILY BY MY SOFTWARE APPLICATION I KNOW ENOUGH TO WORK WITH THE DATA

THE TEMPORAL NOMINAL RESOLUTION IS ADEQUATE THE VERTICAL NOMINAL (GRID CELL SIZE) RESOLUTION IS ADEQUATE WEBSITES PROVIDE GOOD INFORMATION THE SPATIO-TEMPORAL SCALES THAT I NEED ARE WELL REPRESENTED THE FILE SIZES ARE NOT TOO LARGE TO WORK WITH

THE LITERATURE PROVIDES GOOD INFORMATION THE HORIZONTAL NOMINAL (GRID CELL SIZE) RESOLUTION IS ADEQUATE THE DATA DO NOT TEND TO BECOME AVAILABLE TOO LATE FOR MY NEEDS

THE DATA POLICY IS NOT TOO STRICT

THE BIASES COMPARED WITH OBSERVATIONS ARE SMALL ENOUGH TIME-VARYING BIASES DO NOT MAKE THE DATA TOO INSTABLE FOR MY NEEDS FOR THE CLIMATE VARIABLES I NEED, I KNOW HOW MUCH THEIR SPATIAL TRUE I KNOW HOW MUCH THE TEMPORAL TRUE (FEATURE) RESOLUTION DIFFERS FROM THE OBSERVATION INPUT TO REANALYSIS ARE CLEARLY EXPLAINED

PLENTIFUL TRAINING MATERIAL IS AVAILABLE ON THE WEB THE UNCERTAINTIES ARE WELL CHARACTERIZED

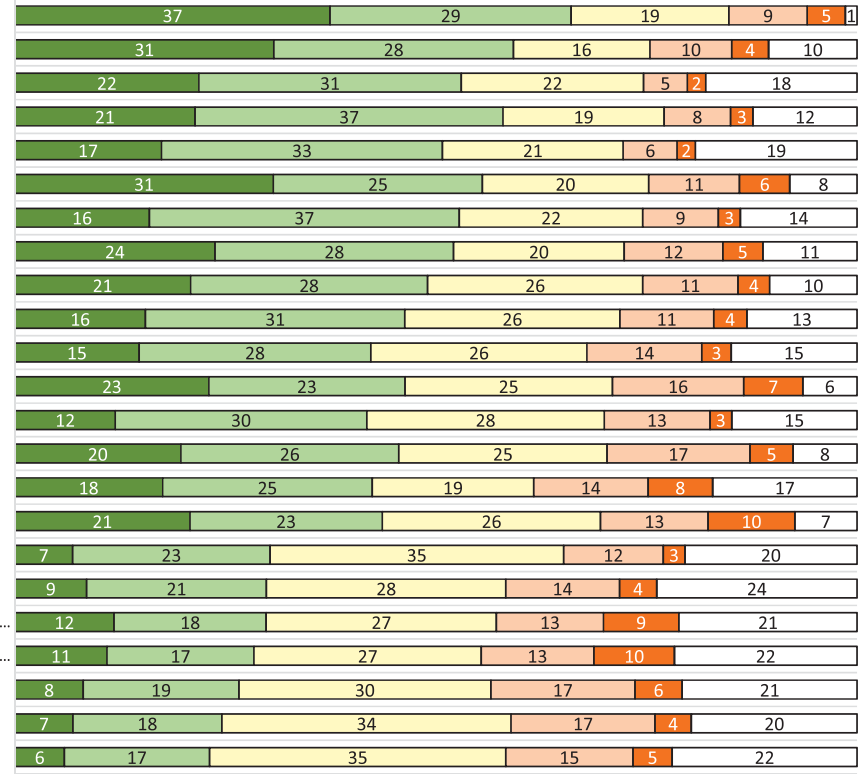

$\square$ Fully agree $\square$ Somewhat agree $\square$ In between $\square$ Somewhat disagree $\square$ Fully disagree $\square$ No response

Fig. 3. Distribution (\%) of agreement with regard to propositions about the characteristics of reanalysis data. The total number of people responding to one or several statements was $\mathbf{2 , 4 8 6}$. The propositions have been sorted according to their mean score (see Table 3).

A)

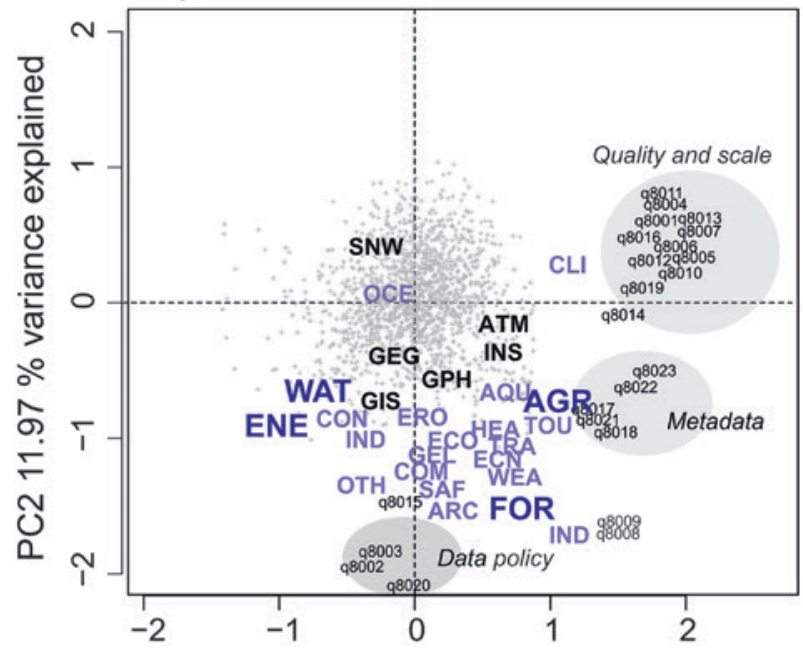

PC1 $27.37 \%$ variance explained
B)

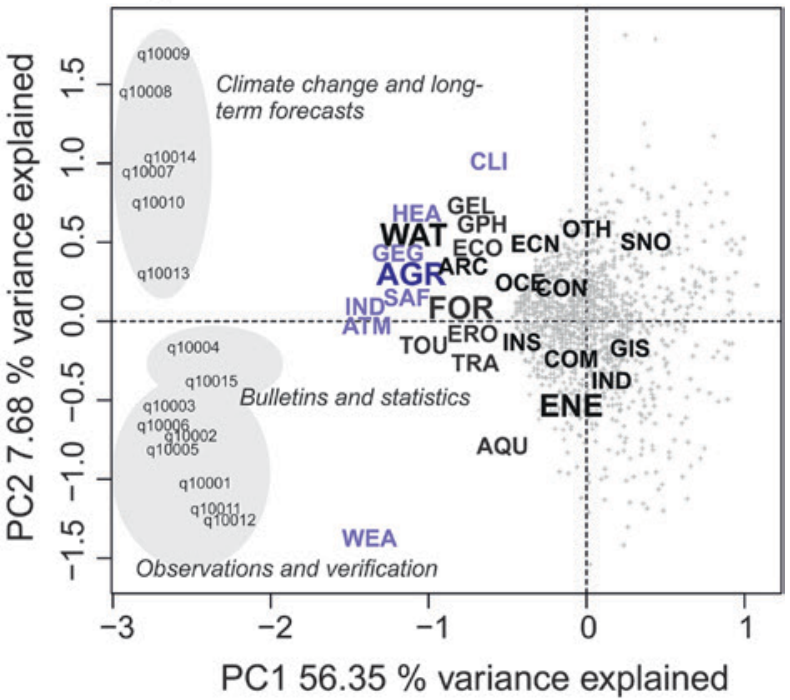

FIG. 4. PCA showing the relative similarity of the answers for (a) Q8 ("Regarding the characteristics of Reanalysis data...") and (b) QI0 ("Regarding future of climate services..."). The abbreviation of the sectors and their position in the ordinations indicate the linear correlation with the answers (distances are scaled by the strength of correlation). The solid gray areas represent answers regarding similar topics (italic font). The sectors with black fonts are not significantly related to the ordination $(p>0.05$; tested with 1,000 random permutation of the data). Sectors are abbreviated as follows: weather (WEA), climate (CLI), air quality (AQU), other aspects of atmosphere (OTH), oceans and sea (OCE), freshwater resources and management (WAT), snow and ice (SMW), agriculture and food production (AGR), forests (FOR), ecosystems and biodiversity (ECO), erosion and flooding of coastal areas (ERO), energy (ENE), industry (IND), transportation (TRA), economics (ECN), insurance (INS), architecture (ARC), construction and municipal engineering (CON), health and human well-being (HEA), tourist and recreation (TOU), safety and security (SAF), indigenous peoples issues (IND), geophysics and geochemistry (CPH), geoinformatics (GIS), geology (GEL), and geography (GEG). 
TABLE 4. Free-form comments concerning use of reanalyses. Two reviewers read through the responses and categorized the needs of users independently.

\section{Reviewer A}

I) The largest share of responses dealt with data access, formats, and quality.

2) Many users hoped for earlier availability of data.

3) Clear representation of uncertainties in the data was considered important.

4) Be able to compare reanalyses; users would like to have training and more online plotting tools.

5) Summer schools and workshops were mentioned and there was a wish that these training could be given in native languages as well.

6) There was an overall recommendation to make the access and downloading of data as easy as possible. Suggested popular data formats included NetCDF.

7) There was a wish to have scripts available to help downloading and to have Windows and OPeNDAP compatibility. Open and free access was also desired.

\section{Reviewer B}

I) Improve resolution and provide longer time series (I46).

2) Consultation, training, and tutorials for, for example, guiding in search of data (96).

3) More parameters that are currently not available (85) (missing data)

4) Data costs were not wanted, and data were desired to be more easily available (64).

5) Data format was considered difficult and suggestions were given (48).

6) Slow downloading bothered (39).

7) Near-real-time or real-time updates were desired (30).

8) Data quality (20).

9) Web page updates to become more user-friendly (I4).

A few percent (3.5\%) of ALL had not used reanalysis products at all but applied climate data from other sources such as in situ, in situ gridded, or satellite data (Tables S2 and S3). It appeared that they slightly more commonly disagreed with the statements "The data can be imported easily by my software application," "The data is easy to access," "I know enough to work with the data," "The file sizes are not too large to work with," "Time-varying biases do not make the data too unstable for my needs," and "The general quality is good enough for my needs."

The principal component analysis revealed that the majority of the variation in the data can be suppressed into the first two components PC1 and PC2 (Tables S4 and S5). With regard to Q8, the two components PC1 (27\%) and PC2 (12\%) explain, in total, 39\% of the variance. The two highest component loadings are temporal nominal resolution and general quality for PC1 and timely availability of the data and data policy for PC2. The Q10 responses regarding the opinions of future climate services can be largely described by $\mathrm{PC} 1$, which explains $56 \%$ of the variance. The component loadings for PC1 are almost invariant, with the detection of climate change and production of long-term climate projections representing only slightly higher loadings than the other components.

Based on the principal component analysis, the answers can roughly be grouped to concern "Quality and scale," "Metadata," and "Data policy" issues (Fig. 4a). Concerning free-form comments about reanalysis data, the largest share of responses dealt with data access, formats, and quality. Many users hoped for earlier availability of data (Table 4).

Respondents' opinions in regard to future climate services. All of the 15 postulated climate service tasks and activities received, on average, positive interest from the survey respondents, as was shown by the PC analysis. The mean scores given by ALL ranged from 3.6 to 4.2 (Table 5) with a mean score of 3.8 (standard deviation of 0.2). For both ALL and the four subgroups, the mean score of each proposition was statistically significantly higher than the midpoint of the Likert scale 3. On the other hand, none of the activities gained a total consensus, as $7 \%-15 \%$ of the respondents did not think that these should be included in future climate services (Fig. 5). The strongest support was expressed by ALL for 
"Interpolation and production of gridded datasets based on observations," "Provision of statistics based on observations," and "Homogenization of weather station data."

It appeared that the four subgroups in general gave somewhat higher scores for the proposed climate service tasks and activities than the respondents outside these subgroups (not shown). The three most consensual activities were the same (even with varying order) in ENE, FOR, and WAT as in ALL (Table 5). Regarding proposed activities outside the top three, FOR valued "Statistical impact analyses for improving weather warnings and their criteria," "Climate change impact consultancy for decision makers," and "Production of long-term climate projections" clearly higher in their priority list than ALL did. AGR and WAT gave, in turn, more emphasis on "Applied weather and climate research for impact assessment," and ENE gave more emphasis on "24/7 updates, in the internet, of statistics of weather and climate" than ALL. Despite these differences, the principal component analysis for Q10 revealed clear similarities in the answers. Three clusters could be identified: "Climate change and long-term forecasts,"
"Bulletins and statistics," and "Observations and verification” (Fig. 4b).

The 2,488 respondents that had used reanalysis for at least one geophysical variable exhibited more distinct polarity in their opinions on the issues of Table 5: the fraction answering "in between 3 " or not at all was on average $44 \%$, whereas it was $60 \%$ for those who had not used reanalysis. In general, the reanalysis users agreed more strongly in all cases: their scores were 5\%-22\% higher than those of the others. The largest difference in response to individual questions was that the people using reanalysis were more in favor (22\%) of the "Provision of statistics based on observations," whereas the others were more uncertain (22\%). Other stronger differences in opinions for or against were that the reanalysis users agreed more strongly about "Monthly forecasting and verification" (20\%), "Homogenization of weather station data" (19\%), and "Interpolation and production of gridded datasets based on observations" (18\%). Otherwise the differences in single questions (other than in between) were at most 15\%. On average, the reanalysis users agreed more by $13 \%$ and disagreed more by $2.6 \%$. The maximum difference in the average scores of individual answers was only 0.32 .

TABLE 5. Opinions of the respondents regarding the climate service tasks and activities. The propositions have been sorted according to their mean scores based on ALL (2,192 respondents to Q10): the higher the score, the more wanted the task or activity would be. Column I provides the statements; columns 2 and 3 show the mean and standard deviation, respectively, of scores according to ALL ( $\mathrm{I}=$ fully disagree, $5=$ fully agree); column 4 shows statistical significance of the difference from the midpoint of the Likert item 3; columns 5-8 show the differences $\Delta$ in priority compared to ALL separately for WAT (I55 respondents), AGR (I3I), FOR (104), and ENE (214). A negative (positive) value implies a lower (higher) priority. The following notation is used: * indicates $0.05<p \leq 0.01$, ** indicates $0.01<p \leq 0.001$, and $* * *$ indicates $p<0.001$.

\begin{tabular}{|c|c|c|c|c|c|c|c|}
\hline Statement about climate services & $\begin{array}{c}\text { ALL } \\
\text { mean }\end{array}$ & $\begin{array}{c}\text { ALL } \\
\text { std dev }\end{array}$ & ALL $p$ & $\begin{array}{c}\text { WAT } \\
\Delta\end{array}$ & AGR $\Delta$ & FOR $\Delta$ & ENE $\Delta$ \\
\hline $\begin{array}{l}\text { Interpolation and production of gridded datasets based on } \\
\text { observations. }\end{array}$ & 4.2 & I.I & **** & -1 & -3 & 0 & -1 \\
\hline Provision of statistics based on observations. & 4.1 & I.I & $* * *$ & -1 & 0 & 0 & -1 \\
\hline Homogenization of weather station data. & 4.1 & 1.1 & $* * *$ & 2 & 2 & 0 & 2 \\
\hline Research and communication of climate change uncertainties. & 4.0 & 1.1 & $* * *$ & 0 & -3 & -8 & 0 \\
\hline Monthly forecasting and verification. & 3.9 & 1.1 & $* * *$ & -2 & 0 & -1 & 0 \\
\hline Detection of climate change. & 3.9 & I.I & $* * *$ & 1 & -3 & -3 & 0 \\
\hline Seasonal forecasting and verification. & 3.9 & 1.2 & **** & -1 & I & 0 & 0 \\
\hline Production of long-term climate projections. & 3.8 & 1.2 & $* * *$ & -1 & 0 & 3 & 0 \\
\hline Applied weather and climate research for impact assessment. & 3.8 & 1.1 & $* * *$ & 3 & 6 & 1 & 0 \\
\hline Provision of statements describing past weather events. & 3.8 & I.I & $* * * *$ & -1 & -1 & -1 & 0 \\
\hline Attribution of climate change. & 3.7 & 1.2 & $* * *$ & I & -2 & -2 & -1 \\
\hline $\begin{array}{l}\text { Statistical impact analyses for improving weather warnings } \\
\text { and their criteria. }\end{array}$ & 3.7 & I.I & $* * *$ & 0 & 2 & 8 & -1 \\
\hline Climate watch bulletins. & 3.6 & 1.1 & $* * * *$ & -1 & -2 & -2 & -2 \\
\hline $24 / 7$ updates, on the Internet, of statistics of weather and climate. & 3.6 & 1.2 & **** & -1 & 2 & 0 & 3 \\
\hline Climate change impact consultancy for decision-makers. & 3.6 & 1.2 & $* * *$ & 2 & I & 5 & I \\
\hline
\end{tabular}


Given the potential for sampling bias arising from the high proportion (91\%) of responses from ECMWF reanalysis users, we make no claim that the opinions expressed by survey respondents on climate service activities should be regarded as fully representative of the wider and time-evolving climate service community. We would, however, be pleased to contribute our sample to more comprehensive compilations of community opinion.

CONCLUSIONS. This paper reports on a survey designed to identify the obstacles to the use of reanalysis in support of future climate services. The results are based on a worldwide survey conducted in winter 2013/14. The contextual background of the survey respondents is indicated by their sector, field of work, and region of focus. The major sectors were public R\&D ( 1,170 out of 2,578 respondents; or $45 \%)$ and education $(941 ; 37 \%)$, and only a minority was from the private sector $(189 ; 7 \%)$. Similar proportions were reported for three of the four selected subgroups: WAT, AGR, and FOR. These consisted of respondents who declared their main field of work to be freshwater resources and management, agriculture and food production, or forests. In contrast, approximately one-third of the respondents from the energy sector (ENE) represented the private sector.

The results from ALL indicated that reanalyses are used in various applications, for instance, when studying atmospheric dynamics and physics and/or working on atmospheric and climate modeling. The

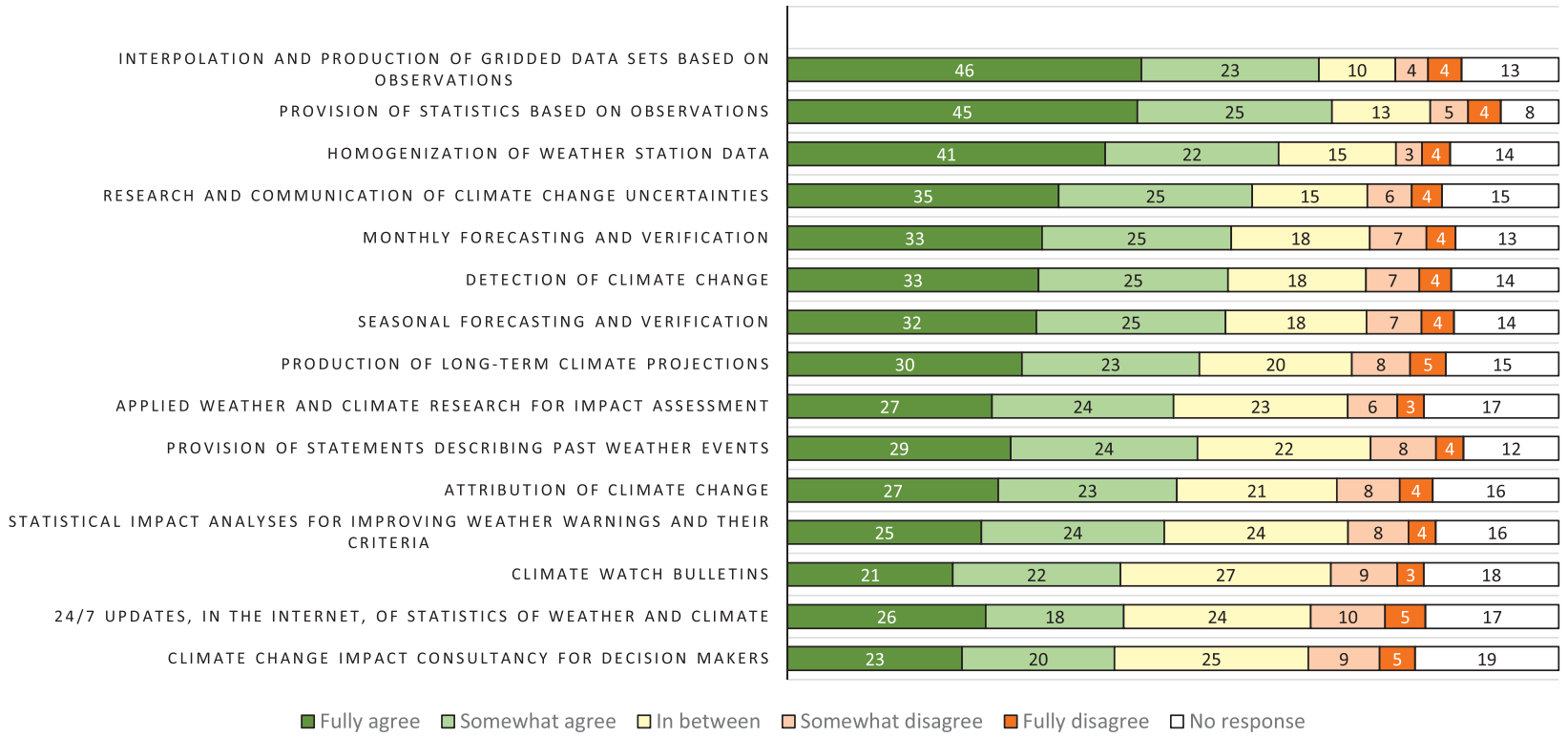

FIG. 5. Distribution (\%) of agreement with regard to propositions about future climate service activities. The total number of people responding to one or several statements was 2,192. The propositions have been sorted according to their mean score (see Table 5). four subgroups also use reanalyses for time series analyses (WAT, AGR, FOR, ENE), for studying climate change impacts (WAT and AGR), for climate change detection (WAT), and for resource assessment for renewable energies (ENE). ALL particularly wish for better characterization and communication of the uncertainties and limitations of the reanalysis data. In addition, they desire less restrictive data policy, more help and information on websites, and faster updates and release of data. ENE and WAT respondents additionally wish for higher temporal and spatial resolution, and WAT also wishes for smaller biases. All of these points are pertinent considerations in the development of the Copernicus Climate Change Service (C3S) and the Global Framework for Climate Services (GFCS).

The respondents acknowledge that they need support to better understand the reanalyses. Summer schools and workshops were desired in the free-form answers by the four subgroups, who also expressed a need to have more ready-made scripts and tools to help downloading. If such support services were to be provided in native languages, it would be very much appreciated at least by some of the respondents. Reanalysis uptake as part of the future climate services could thus be increased by capacity building and by enhancing the outreach and dissemination activities. Some aspects of the capacity building would need to be undertaken by the data provider community, while other aspects would need to be undertaken by the data user community. We note the potential for different national bodies to provide native language 
support and encourage them to engage in the planning and implementation of the C3S outreach and dissemination (OD) as well as the GFCS capacity building (CB) future activities. Capacity building to characterize and understand dataset uncertainties, including the development of analytical techniques and provision of data evaluation tools, is of strategic importance and will require sustained effort.

Survey responses expressing interest in the delivery of tailored monthly to seasonal-scale forecasting for agriculture applications could be of interest to the research, modeling, and prediction (RMP) pillar of the GFCS. A similar conclusion concerning agriculture (and food production) was presented by Tall et al. (2014) who stated that the components within a climate service would need a seamless suite of forecast (subdaily to at least seasonal), advisory, and early warning products to help farmers manage evolving risks during the growing season with large enough lead time.

We caution against overinterpreting these results, particularly where sampling and response biases may affect representativeness; 1,332 (52\%) responses came within five days after NOAA and ECMWF had advertised the survey on 21-22 January 2014, and an additional $860(33 \%)$ responses arrived after the second e-mailing by ECMWF on 24 February 2014. Respondents using non-ECMWF reanalyses amounted to 1,010 (39\%) using NCEP-NCAR (R1), 592 (23\%) using NCEP-DOE AMPI-II (R2), 572 (22\%) using NCEP (CFSR), 349 (14\%) using Japan Meteorological Agency (JMA) Japanese 25-year Reanalysis Project (JRA-25), and 60 (2\%) using the Japan Meteorological Agency Climate Data Assimilation System (JCDAS). Their responses allow identification of developments that would increase the user uptake of reanalyses more generally.

Counts of using various reanalysis datasets are of course influenced by many factors, including the population we were able to reach in the survey and the time that respondents had to familiarize themselves with the datasets, so it is not surprising that relatively new reanalyses such as JMA's JCDAS have lower counts. Usage counts are arguably most informative when tracked over time in a succession of surveys.

Existing reanalysis users represent one portion of the future climate services community that is itself anticipated to grow as the availability of climate information improves and new applications are developed. We recommend that further steps be taken to ascertain more comprehensively the needs of the wider climate services community and offer our results as a contribution to the broader effort. The responses of this survey are most suited to studies of the characteristics and use of reanalysis data. In the future, our investigations will concentrate on the differences between users' views of the various reanalyses and datasets, user applications, and fields of work such as safety and insurance.

ACKNOWLEDGMENTS. This work was financially supported by the EU FP7 CORE-CLIMAX project. Satu Kekki is thanked for the technical design of the Webropol survey. We thank Carsten Maass from ECMWF for arranging e-mailing about 24,000 ECMWF users, Karolin Eichler from WMO for helping distribute the survey to the WMO regional offices, Gil Compo from CIRES for advertising the survey in the United States, and Shinya Kobayashi for advertising the survey to users of JMA reanalyses. We are very grateful to all of the respondents for giving their time to take part in the survey. Prof. Ari Laaksonen is thanked for commenting on the manuscript. We are thankful for the two referees for their valuable comments that helped us improve the paper.

\section{REFERENCES}

Aalto, J., P. Pirinen, J. Heikkinen, and A. Venäläinen, 2013: Spatial interpolation of monthly climate data for Finland: Comparing the performance of kriging and generalized additive models. Theor. Appl. Climatol., 112, 99-111, doi:10.1007/s00704-012-0716-9.

Becker, A., P. Finger, A. Meyer-Christoffer, B. Rudolf, K. Schamm, U. Schneider, and M. Ziese, 2013: A description of the global land-surface precipitation data products of the Global Precipitation Climatology Centre with sample applications including centennial (trend) analysis from 1901present, Earth Syst. Sci. Data, 5, 71-99, doi:10.5194 lessd-5-71-2013.

Bosilovich, M. G., J. Kennedy, D. Dee, R. Allan, and A. O'Neill, 2013: On the reprocessing and reanalysis of observations for climate. Climate Science for Serving Society: Research, Modelling and Prediction Priorities, A. Ghassem and J. W. Hurrell, Eds., Springer, 51-71, doi:10.1007/978-94-007-6692-1_3.

Bradwell, P., and S. Marr, 2008: Making the most of collaboration: An international survey of public service co-design. DEMOS Rep. 23, 53 pp. [Available online at www.demos.co.uk/files/CollabWeb.pdf.]

Dee, D. P., and Coauthors, 2011: The ERA-Interim reanalysis: Configuration and performance of the data assimilation system. Quart. J. Roy. Meteor. Soc., 137, 553-597, doi:10.1002/qj.828.

, M. Balmaseda, G. Balsamo, R. Engelen, A. J. Simmons, and J.-N. Thépaut, 2014: Toward a consistent 
reanalysis of the climate system. Bull. Amer. Meteor. Soc., 95, 1235-1248, doi:10.1175/BAMS-D-13-00043.1.

Gregow, H., and Coauthors, 2015: User awareness concerning reanalysis feedback data and input observations. Adv. Sci. Res., 12, 63-67, doi:10.5194/ asr-12-63-2015.

Hartmann, D. L., and Coauthors, 2013: Observations: Atmosphere and surface. Climate Change 2013: The Physical Science Basis, T. F. Stocker et al., Eds., Cambridge University Press, 159-254.

Hewitt, C., S. Mason, and D. Walland, 2012: The Global Framework for Climate Services. Nat. Climate Change, 2, 831-832, doi:10.1038/nclimate1745.

Hofstra, N., M. Haylock, M. New, P. Jones, and C. Frei, 2008: Comparison of six methods for the interpolation of daily, European climate data, J. Geophys. Res., 113, doi:10.1029/2008JD010100.

Hofstra, N., M. New, and C. McSweeney, 2010: The influence of interpolation and station network density on the distributions and trends of climate variables in gridded daily data. J. Climate Dyn., 35, 841-858, doi:10.1007/s00382-009-0698-1.

Hollingsworth, A., and C. Pfrang, 2005: A preliminary survey of ERA-40 users developing applications of relevance to GEO (Group on Earth Observations). ECMWF Newsletter, No. 104, ECMWF, Reading, United Kingdom, 5-9.

McNie, E. C., 2013: Delivering climate services: Organizational strategies and approaches for producing useful climate-science information. Wea. Climate Soc., 5, 14-26, doi:10.1175/WCAS-D-11-00034.1.

Menne, M. J., I. Durre, R. S. Vose, B. E. Gleason, and T. G. Houston, 2012: An overview of the Global Historical Climatology Network-Daily database. J. Atmos. Oceanic Technol., 29, 897-910, doi:10.1175 /JTECH-D-11-00103.1.

Oksanen, J., R. Kindt, P. Legendre, B. O’Hara, L. G. Simpson, and M. H. H. Stevens, 2008: Vegan: Community
Ecology Package. R-Forge. [Available online at http:// vegan.r-forge.r-project.org/.]

Poli, P., and Coauthors, 2013: The data assimilation system and initial performance evaluation of the ECMWF pilot reanalysis of the 20th-century assimilating surface observations only (ERA-20C). ERA Rep. Series 14, 59 pp. [Available from ECMWF, Shinfield Park, Reading, United Kingdom.]

R Development Core Team, 2013: R: A Language and Environment for Statistical Computing. R Foundation for Statistical Computing, $409 \mathrm{pp}$.

Street, R., M. Parry, J. Scott, D. Jacob, T. Runge, 2015: A European research and innovation roadmap for climate services. Luxembourg: Publications Office of the European Union, doi:10.2777/750202.

Tall, A., J. Hansen, A. Jay, B. Campbell, J. Kinyangi, P. K. Aggarwal, and R. Zougmoré, 2014: Scaling up climate services for farmers: Mission possible. Learning from good practice in Africa and South Asia. CGIAR Research Program on Climate Change, Agriculture and Food Security Rep. 13, 44 pp. [Available online at https://cgspace.cgiar.org/handle/10568/42445.]

Uppala, and Coauthors, 2005: The ERA-40 re-analysis. Quart. J. Roy. Meteor. Soc., 131, 2961-3012, doi:10.1256 /qj.04.176.

WMO, 2011: Climate knowledge for action: A global framework for climate services-Empowering the most vulnerable-Frequently asked questions relating to the report of the high-level taskforce for the Global Framework for Climate Services. World Meteorological Organization Rep. 1065, 20 pp. [Available online at www.gfcs-climate.org/sites /default/files/FAQ/HLT/HLT_FAQ_en.pdf.]

Woodruff, S. D., and Coauthors, 2011: ICOADS release 2.5: Extensions and enhancements to the surface marine meteorological archive. Int. J. Climatol., 31, 951-967, doi:10.1002/joc.2103. 


\section{EYEWITNESS}

\section{EVOlution of the AtMospheric Sciences}

\section{by ROBERT G. FLEAGLE}

Eyewitness: Evolution of the Atmospheric Sciences describes how the atmospheric sciences were transformed in the span of the author's professional career from its origins in primitive weather forecasting to its current focus on numerical modeling of environmental change. It describes the author's observations of persons, events, and institutions beginning with graduate study during the Second World War and

moving on to continuing expansion of the atmospheric sciences and technologies, through development of a major university department, development of new scientific and professional institutions, and to the role that the science of the atmosphere now plays in climate change and other issues of social and political policy.

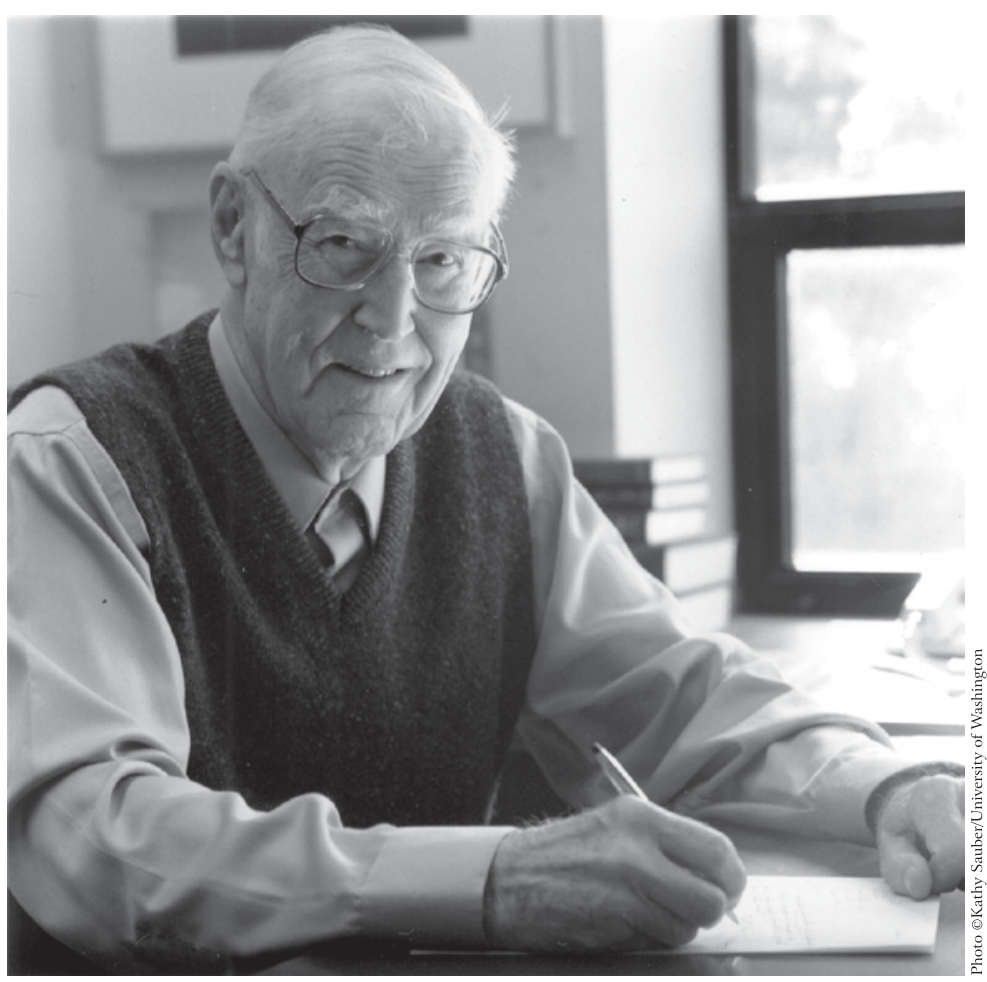

EYEWITNESS: EVOLUTION OF THE ATMOSPHERIC SCIENCES

ISBN 1-878220-39-X, 129 pp., hardbound, \$75 list/\$55 member.

Order online: www.ametsoc.org/amsbookstore

or see the order form at the back of this issue.

\section{ABOUT THE AUTHOR}

Robert G. Fleagle earned degrees in physics and meteorology at The Johns Hopkins University and New York University and began his professional career in 1948 at the University of Washington (UW). His research has focused on the structure of midlatitude cyclones, the physics and structure of the surface boundary layer, and processes of air-sea interaction. He is the author of about 100 papers published in scientific journals and of books on atmospheric physics and global environmental change. Applications of science to social and political policy have been important motivations for his career and have occupied his attention increasingly as the decades passed.

Fleagle participated at close range in the beginnings and growth of a major university department and of the University Corporation for Atmospheric Research (UCAR). In 1963 and 1964 he served as a staff specialist in the Office of Science and Technology, Executive Office of the President, and in 1977-78 he served as consultant to the National Oceanic and Atmospheric Administration. He has held many administrative posts including chairman of the UW Department of Atmospheric Sciences (1967-77), chairman of the National Academy of Sciences Committee on Atmospheric Sciences (1969-73), 